\title{
Deposition of Low Stress Silicon Nitride Thin Film and Its Application in Surface Micromachining Device Structures
}

\author{
Beirong Zheng, ${ }^{1}$ Chen Zhou, ${ }^{1}$ Quan Wang, ${ }^{2}$ Yifeng Chen, ${ }^{1}$ and Wei Xue \\ ${ }^{1}$ College of Mechanical and Electrical Engineering, Wenzhou University, Wenzhou 323035, China \\ ${ }^{2}$ State Key Lab of Transducer Technology, Chinese Academy of Sciences, Shanghai 200050, China \\ Correspondence should be addressed to Wei Xue; xue_wenzhou@163.com
}

Received 26 July 2013; Accepted 23 September 2013

Academic Editor: Yan Yang

Copyright (c) 2013 Beirong Zheng et al. This is an open access article distributed under the Creative Commons Attribution License, which permits unrestricted use, distribution, and reproduction in any medium, provided the original work is properly cited.

\begin{abstract}
Surface machining processes are responsible for creating microstructures that reside near the surfaces of a substrate and are characterized by the fabrication of micromechanical structures from deposited thin films. These films can be selectively removed to build three-dimensional structures whose functionality typically requires that they should be freed from the planar substrate. Silicon nitride thin film is one of these important materials. In this paper, by adjusting the $\mathrm{SiH}_{2} \mathrm{Cl}_{2} / \mathrm{NH}_{3}$ gaseous ratio, low stress silicon nitride (LS SiN) is deposited by the low pressure chemical vapor deposition (LPCVD) process. The internal stress generally in $135 \mathrm{MPa}$ has been detected using an FLX-2320 film stress tester. Based on the wide application in surface micromachining devices, the mechanical properties of LS SiN are measured by nanoindentation, giving the value of Young's modulus of $224 \mathrm{GPa}$ and the hardness of $22.5 \mathrm{GPa}$, respectively. Dry etching and wet etching are utilized to fabricate the LS SiN thin film for structural layers. The etching rate compared with normal $\mathrm{Si}_{3} \mathrm{~N}_{4}$ film by LPCVD is demonstrated for silicon chip manufacture.
\end{abstract}

\section{Introduction}

Bulk micromachining is an important class of micromechanical electronics system (MEMS) process $[1,2]$. In bulk processes, a portion of the substrate (bulk) is removed in order to create freestanding mechanical structures (such as beam and membranes) or unique three-dimensional features (such as cavities, through-wafer holes, and mesas). There are two major categories of processes for bulk etching according to the medium of the etchant: wet etching and dry etching. Wet silicon etching processes use liquid chemical solutions in contact with silicon. Dry etching uses plasma (high energy gas containing ionized radicals) or vapor phase etchants to remove materials. Currently, the focus on the bulk etching has been transformed from the etching geometric structures to improving etching accuracy, uniformity, surface roughness, and compatibility with CMOS.

Surface micromachining is so named because the process takes place on the surface of the wafer, where films are used for structural elements and deposited using a technique such as low temperature chemical vapor deposition (LPCVD) $[3,4]$. Originally, employed for integrated circuits, films composed of materials such as polysilicon, silicon nitride, and silicon dioxides can be sequentially deposited and selectively removed or machine three-dimensional structures whose functionality typically requires that they should be freed from the planar substrate. Bulk micromachining is not easily integrated with IC processing. Surface micromachining can easily be integrated with CMOS processing, allowing signal processing circuitry and MEMS devices to exist on the same chip.

There are two key process steps in surface micromachining. The first is deposition of low stress thin films that can be used for structural elements. The second is the use of a sacrificial layer to allow the structural layer to be detached from the substrate, thus allowing the motion of the structural layer. The deposition of controlled stress films is an essential process step for surface micromachining. With excellent characteristics $[5,6]$, silicon nitride film can block the diffusion of water and ions (such as sodium) effectively. Due to the capability of antioxidization and anticorrosion, it can be used as masks for deep etching, electronic insulation layer, and ion implantation. In this paper, we focus on the preparation process of low stress silicon-rich nitride 
(LS SiN) films. The mechanical parameter of LS SiN is presented by nanoindentation. The film pattern in the surface micromachining process is demonstrated, which provides a strong basis for the MEMS device design and silicon chip fabrication.

\section{Deposition of Low Stress Silicon Nitride Thin Film}

Normal $\mathrm{Si}_{3} \mathrm{~N}_{4}$ film is deposited at temperature over $800^{\circ} \mathrm{C}$ using dichlorosilane (DCS) and ammonia in a flow ratio of approximately $1: 5\left(\mathrm{DCS}: \mathrm{NH}_{3}\right)$ on a silicon wafer. This process yields a stoichiometric $\mathrm{Si}_{3} \mathrm{~N}_{4}$ film with high tensile stress. By reversing the flow ratio to $10: 1$, a silicon-rich nitride film is deposited, and the tensile stress level is considerably lower. Table 1 lists the parameters; the reaction is

$$
\mathrm{SiCl}_{2} \mathrm{H}_{2}+\mathrm{NH}_{3} \longrightarrow \mathrm{SiN}+\mathrm{HCl}+\mathrm{H}_{2}
$$

Figure 1 depicts the stress map of LS SiN tested by FLX2320. The stress can be calculated using the Stoney equation as follows:

$$
\sigma=\frac{\delta}{t} \frac{E}{1-v} \frac{T^{2}}{3 R^{2}},
$$

where $\delta$ and $t$ are the deflection of wafer center and film thickness, respectively. $R$ and $T$ are the radius and thickness of silicon, respectively. $E$ is Young's modulus, and $v$ is Poisson's ratio. The fitted stress is less than $135 \mathrm{MPa}$.

\section{Mechanical Properties of LS SiN}

In MEMS/NEMS design, Young's modulus of the thin film is one of the important mechanical properties. Young's modulus of a single-crystal material reflects the details of interatomic bond energy and lattice structure. With the rapid development of NEMS technologies, ultrathin cantilevers have been used as sensitive sensors for applications involving ultrafine resolution. Young's modulus, E, has a strong effect on the resonant cantilevers because it is proportional to the square of the resonance frequency. The fundamental resonance frequency of a cantilever is [7]

$$
f_{0} \approx 0162 \frac{t}{l^{2}} \sqrt{\frac{E}{\rho}},
$$

where $t$ is the thickness, $l$ is the length, and $\rho$ is the material density of the cantilever.

Nanoindentation is a useful technique for measuring the mechanical properties of small volumes of materials. Its attractiveness stems largely form the fact that mechanical properties can be determined directly from measurements of indentation and displacement, without the need to image the hardness impression. Based on the depth-sensing indentation method of Oliver and Pharr, the elastic modulus of the
TABLE 1: LS SiN deposition parameter.

\begin{tabular}{lccccc}
\hline \multicolumn{3}{c}{ Temperature $\left({ }^{\circ} \mathrm{C}\right)$} & \multirow{2}{*}{ Pressure (mTorr) } & \multicolumn{2}{c}{ Gas $(\mathrm{sccm})$} \\
Handle & Centre & Source & & $\mathrm{NH}_{3}$ & DCS \\
\hline 835 & 875 & 860 & 289 & 8 & 80 \\
\hline
\end{tabular}

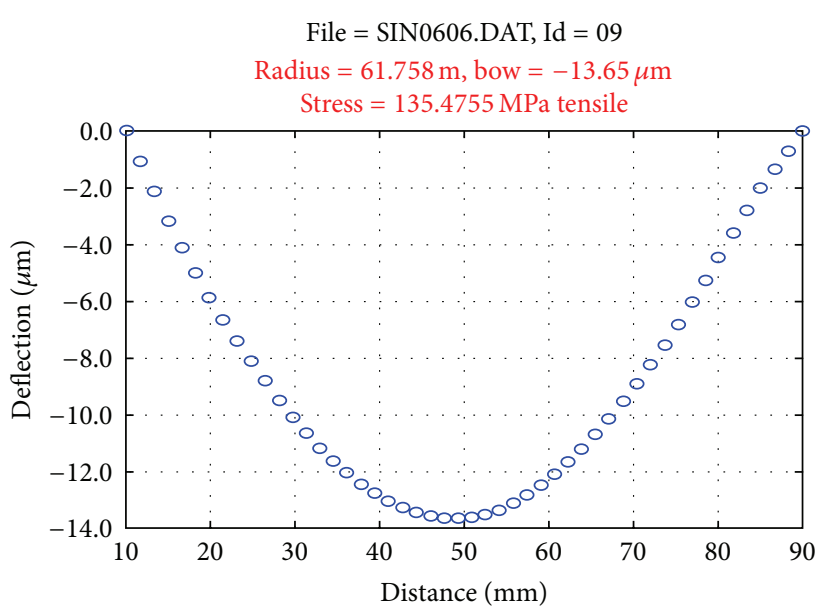

FIGURE 1: Internal stress measurement of LS SiN.

specimen was related to the measured reduced modulus, $E_{r}$, by using the equation $[8,9]$

$$
\begin{gathered}
\frac{1}{E_{r}}=\frac{\left(1-v^{2}\right)}{E}+\frac{\left(1-v_{i}^{2}\right)}{E_{i}}, \\
E=\frac{1-v^{2}}{E_{i}-\left(1-v_{i}^{2}\right) E_{r}} E_{i} E_{r}=\frac{1-v^{2}}{E_{i} / E_{r}-\left(1-v_{i}^{2}\right)} E_{i},
\end{gathered}
$$

where $E_{i}$ and $v_{i}$ are Young's modulus and Poisson's ratio of the diamond tip. Here, $E_{i}$ and $v_{i}$ are equal to $1140 \mathrm{GPa}$ and 0.07 , respectively. $E_{r}$ is referred to as the reduced modulus and is expressed as a function of the displacement per unit load which is applied as follows:

$$
E_{r}=\frac{1}{2} \frac{\sqrt{\pi}}{\sqrt{A}} \frac{d P}{d h} .
$$

In the previous equation (5), $P$ is the applied load, $h$ is the displacement, and $A$ is the contact area.

Nanoindentation tests were carried out on a Triboindenter (Hysitron Inc.), with a Berkovich indenter tip, whose radius was estimated to be $100 \mathrm{~nm}$. Because the thickness of the LS SiN film was around $1.2 \mu \mathrm{m}$, the maximum indentation depth was restricted to $120 \mathrm{~nm}$ to avoid the influence of the substrate. Figure 2 shows the load-displacement relationship of the sample during nanoindentation.

Figure 3 shows the load and unload time. Since the $\mathrm{SiN}$ film thickness is around $1.2 \mu \mathrm{m}$, the $4 \mathrm{mN}$ maximum load, the $5 \mathrm{~s}$ loading time, the $5 \mathrm{~s}$ unloading time, and the $5 \mathrm{~s}$ no-load time are selected to avoid phase change of the material $[10,11]$. The maximum penetration depth to press is less than $120 \mathrm{~nm}$ to avoid the impact of the substrate. Four measurement locations are selected in each sample, each adjacent point 


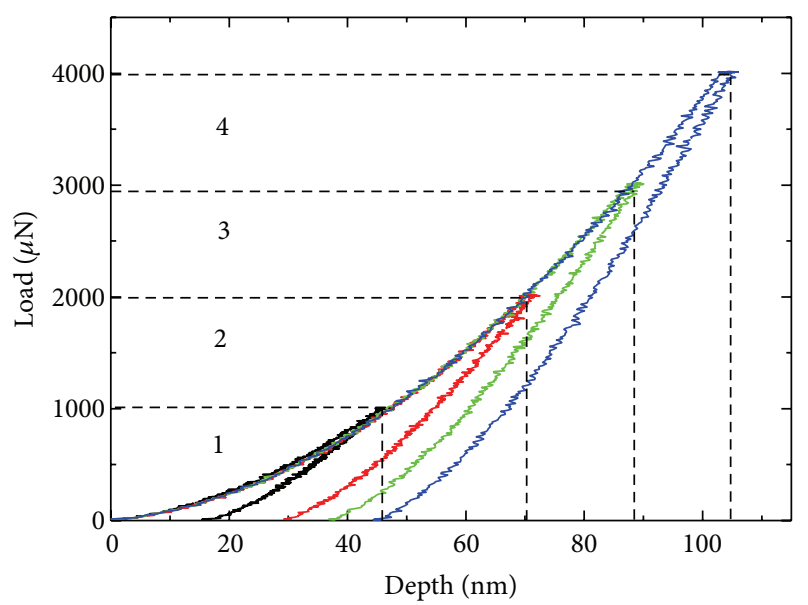

FIGURE 2: Load-displacement relationship of LS SiN sample during nanoindentation.

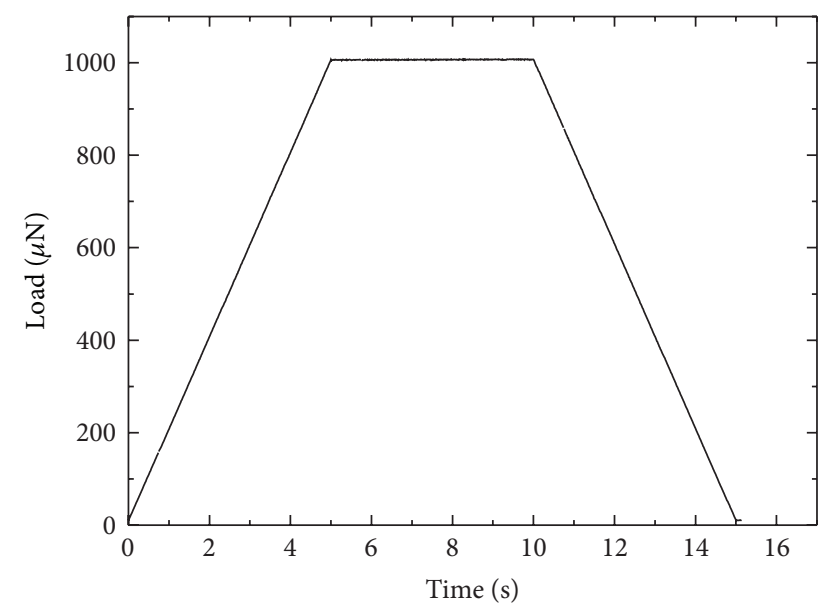

FIGURE 3: Indentation profile used for the indentation experiments.

keeping a distance above $3 \mu \mathrm{m}$. Young's modulus of the four samples calculated is shown in Table 2. The average Young's modulus of LS SiN is $224 \mathrm{GPa}$.

\section{Application of Low Stress Silicon Nitride Film}

Surface micromachining process can fabricate the micromechanical structures adhered to substrate surface by depositing structural layer on the sacrificial one. This can provide support for structural layer and play a role on space-based positioning during processing. The sacrificial layer was then removed to release the structural layer on it. Generally, silicon nitride films deposited by LPCVD can be used as a structural layer for their internal tensile stress and native nonporous morphology. In practical applications, except for long process time (high cost), silicon nitride films by LPCVD are less than $1.5 \mu \mathrm{m}$. If the thickness is too large, the film under tensile stress will bend and even fracture. As the structural layer of devices, films with appropriate internal tensile stress are
TABLE 2: LS SiN Young's modulus experiment.

\begin{tabular}{lcccccc}
\hline \multirow{2}{*}{ Sample } & 1 & 2 & 3 & 4 & Average & $E(\mathrm{GPa})$ \\
& 1 & $E_{r}(\mathrm{GPa})$ & \\
\hline 1P19 & 197.29 & 181.02 & 183.15 & 196.27 & 189.43 & 214.92 \\
$1 \mathrm{P} 20$ & 219.53 & 221.14 & 203.86 & 201.09 & 211.40 & 245.48 \\
$1 \mathrm{P} 21$ & 211.28 & 188.60 & 191.03 & 191.17 & 195.52 & 223.24 \\
1P22 & 187.31 & 186.96 & 187.41 & 189.42 & 187.78 & 212.67 \\
\hline \multicolumn{7}{c}{ Average $(\mathrm{GPa})$} \\
\hline
\end{tabular}

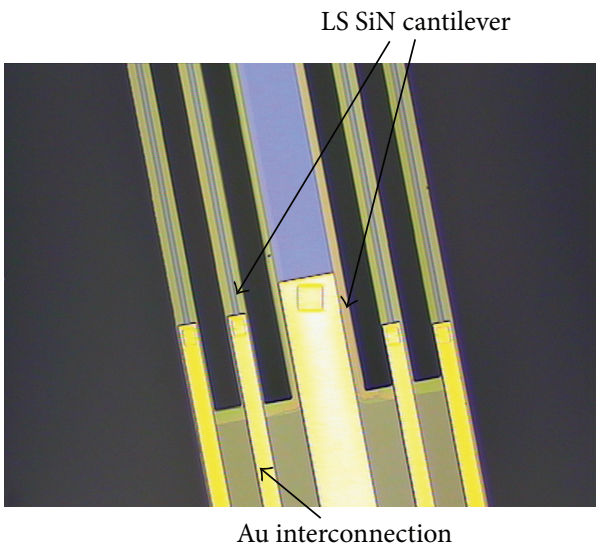

FIGURE 4: Cantilever structure made from LS SiN as the structural layer.

beneficial for the stability of the device and possess good mechanical properties [12]. Figure 4 shows the cantilever beam structure fabricated by LS SiN films. The resistor was formed after depositing polysilicon, ion implantation doping, and photolithography. A circuit compatible with CMOS by sputtering metals was constituted to fulfill low cost mass production of the devices.

The LS SiN patterning process can be divided into dry and wet etching. LS SiN dry etching mainly includes reaction ion etching (RIE) and ion beam etching (IBE). Reaction ion etching (RIE) is a technology that uses chemical reaction and physical ion bombardment to remove material. In general, the $\mathrm{CF}_{4}$ is used as corrosive gas and dissociated into $\mathrm{F}^{*}, \mathrm{CF}_{3}$, $\mathrm{CF}_{2}$ and $\mathrm{CF}$, and so forth. With the highest chemical activity, fluoride free radicals $\mathrm{F}^{*}$ can react with LS SiN; the reaction is as follows:

$$
\mathrm{SiN}+\mathrm{F}^{*} \longrightarrow \mathrm{SiF}_{4} \uparrow+\mathrm{N}_{2} \uparrow
$$

Ion beam bombardment, using the inert gas Argon (Ar) rather than chemical incorporation of etching matter, is an absolute micromachining process with two significant advances of directionality and practicality. Since ions in the ion beam are accelerated by a strong vertical electric field and the pressure in the reactor is extremely low, the impossibility of collisions between atoms leads to the directionality of etching. Firstly, the velocity when atoms impinge the silicon surface is almost vertical. The anisotropic etching to every material can be achieved as a result of its nonchemical property. Secondly, different raw materials used for corrosion 
TABLE 3: LPCVD nitride etching rate comparison.

\begin{tabular}{lccc}
\hline \multirow{2}{*}{ Etchants } & \multirow{2}{*}{ Temperature $\left({ }^{\circ} \mathrm{C}\right)$} & \multicolumn{2}{c}{ Ratio $(\mathrm{A} / \mathrm{min})$} \\
& & Normal Si $_{3} \mathrm{~N}_{4}$ & LS SiN \\
\hline $\mathrm{BOE}$ & 38 & 26.36 & 11.17 \\
$\mathrm{BOE}$ & 25 & 7.68 & 2.66 \\
$\mathrm{KOH}$ & 50 & 0.05 & 0.01 \\
$40 \% \mathrm{HF}$ & 25 & 112.76 & 41.54 \\
$\mathrm{H}_{3} \mathrm{PO}_{4}$ & 160 & 32.56 & 9.95 \\
\hline
\end{tabular}

include compounds and alloys. Due to its capabilities to etch graphics on different materials, the serious disadvantages are the optical photoresistance and the selectivity of lower levels close to $1: 1$.

Due to the selectivity of etching, silicon nitride film commonly functions as a mask for wet etching of polysilicon, silicon oxide, and other materials. A comparison of the etching velocity of normal $\mathrm{Si}_{3} \mathrm{~N}_{4}$ and LS SiN using common etchants was studied. The result of the test is shown in Table 3. Results of the comparison show that the etching rate of normal $\mathrm{Si}_{3} \mathrm{~N}_{4}$ is faster than LS SiN in five different etching solutions $\left(38^{\circ} \mathrm{C} \mathrm{BOE}\right.$, ambient BOE, $50^{\circ} \mathrm{C} \mathrm{KOH}$, ambient $40 \%$ $\mathrm{HF}$, and $\left.160^{\circ} \mathrm{C} \mathrm{H}_{3} \mathrm{PO}_{4}\right)$.

The etching rate of LS SiN in the $\mathrm{KOH}$ and the ambient BOE is so slow that it can be used as a good etching resistant barrier. In the ambient $40 \% \mathrm{HF}$, due to the sensitivity to the oxygen residue in the film, the etching rate as the content of oxygen increased, while it is slow in $\mathrm{H}_{3} \mathrm{PO}_{4}$.

\section{Conclusions}

The preparation of low stress silicon-rich nitride films (LS $\mathrm{SiN}$ ) is presented in this paper. By adjusting the $\mathrm{SiH}_{2} \mathrm{Cl}_{2} / \mathrm{NH}_{3}$ gaseous ratio, $\mathrm{LS} \mathrm{SiN}$ is deposited by the low pressure chemical vapor deposition (LPCVD) process. The internal stress, generally in $135 \mathrm{MPa}$, has been detected using an FLX2320 film stress tester. Based on the wide application in surface micromachining devices, the mechanical properties of LS SiN are measured by nanoindentation, gaining the value of Young's modulus of $224 \mathrm{GPa}$ and the hardness of 22.5 GPa, respectively. Dry etching (reaction ion etching and ion beam etching) and wet etching $\left(38^{\circ} \mathrm{C} \mathrm{BOE}\right.$, ambient $\mathrm{BOE}$, $50^{\circ} \mathrm{C} \mathrm{KOH}$, ambient $40 \% \mathrm{HF}$, and $160^{\circ} \mathrm{C}_{3} \mathrm{PO}_{4}$ ) are utilized to fabricate the LS SiN thin film for structural layers. The etching rate compared with normal $\mathrm{Si}_{3} \mathrm{~N}_{4}$ film by LPCVD is demonstrated for the device silicon chip manufacture.

\section{Acknowledgments}

This work was financially supported by the Science and Technology Development Plan of Zhejiang Province (Public Technology Research and Industrial Projects, Grant no. 2012C21088), Natural Science Foundation of Zhejiang province (Grant no. LY13E050016), and the Opening Foundation of Jiangsu Province Naterial Tribology Key Laboratory (no. kjsmcx1001).

\section{References}

[1] G. T. A. Kovacs, N. I. Maluf, and K. E. Petersen, "Bulk micromachining of silicon," Proceedings of the IEEE, vol. 86, no. 8, pp. 1536-1551, 1998.

[2] M. Zahedinejad, S. D. Farimani, M. Khaje et al., "Deep and vertical silicon bulk micromachining using metal assisted chemical etching," Journal of Micromechanics and Microengineering, vol. 23, no. 5, Article ID 055015, 2013.

[3] F. Nabki, T. A. Dusatko, S. Vengallatore, and M. N. ElGamal, "Low-stress CMOS-compatible silicon carbide surfacemicromachining technology-part I: process development and characterization," Journal of Microelectromechanical Systems, vol. 20, no. 3, Article ID 5742665, pp. 720-729, 2011.

[4] J. M. Bustjllo, R. T. Howe, and R. S. Muller, "Surface micromachining for microelectromechanical systems," Proceedings of the IEEE, vol. 86, no. 8, pp. 1552-1574, 1998.

[5] P. Morin, G. Raymond, D. Benoit, P. Maury, and R. Beneyton, "A comparison of the mechanical stability of silicon nitride films deposited with various techniques," Applied Surface Science, vol. 260, pp. 69-72, 2012.

[6] M. Cazzanelli, F. Bianco, E. Borga et al., "Second-harmonic generation in silicon waveguides strained by silicon nitride," Nature Materials, vol. 11, no. 2, pp. 148-154, 2012.

[7] C. Liu, Foundation of MEMS (2nd Edited), China Machine Press, Beijing, China, 2011.

[8] W. C. Oliver and G. M. Pharr, "Measurement of hardness and elastic modulus by instrumented indentation: advances in understanding and refinements to methodology," Journal of Materials Research, vol. 19, no. 1, pp. 3-20, 2004.

[9] W. C. Oliver and G. M. Pharr, "Improved technique for determining hardness and elastic modulus using load and displacement sensing indentation experiments," Journal of Materials Research, vol. 7, no. 6, pp. 1564-1583, 1992.

[10] S. Ruffell, J. E. Bradby, and J. S. Williams, "High pressure crystalline phase formation during nanoindentation: amorphous versus crystalline silicon," Applied Physics Letters, vol. 89, no. 9, Article ID 091919, 2006.

[11] J. W. Yan, H. Takahashi, J. Tamaki, X. Gai, and T. Kuriyagawa, "Transmission electron microscopic observation of nanoindentations made on ductile-machined silicon wafers," Applied Physics Letters, vol. 87, no. 21, Article ID 211901, pp. 1-3, 2005.

[12] L. W. Lin, H. C. Chu, and Y. W. Lu, "Simulation program for the sensitivity and linearity of piezoresistive pressure sensors," Journal of Microelectromechanical Systems, vol. 8, no. 4, pp. 514$522,1999$. 

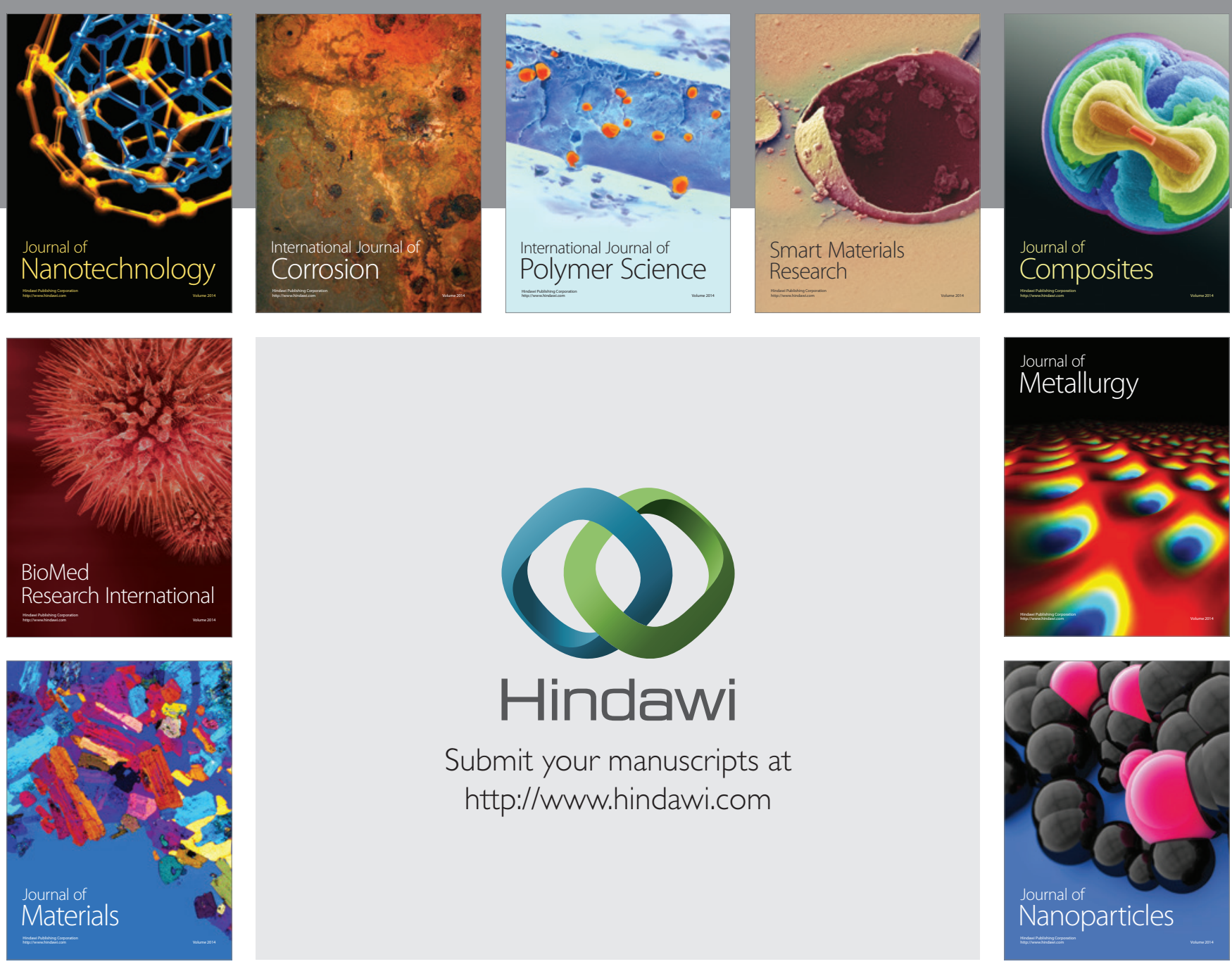

Submit your manuscripts at http://www.hindawi.com
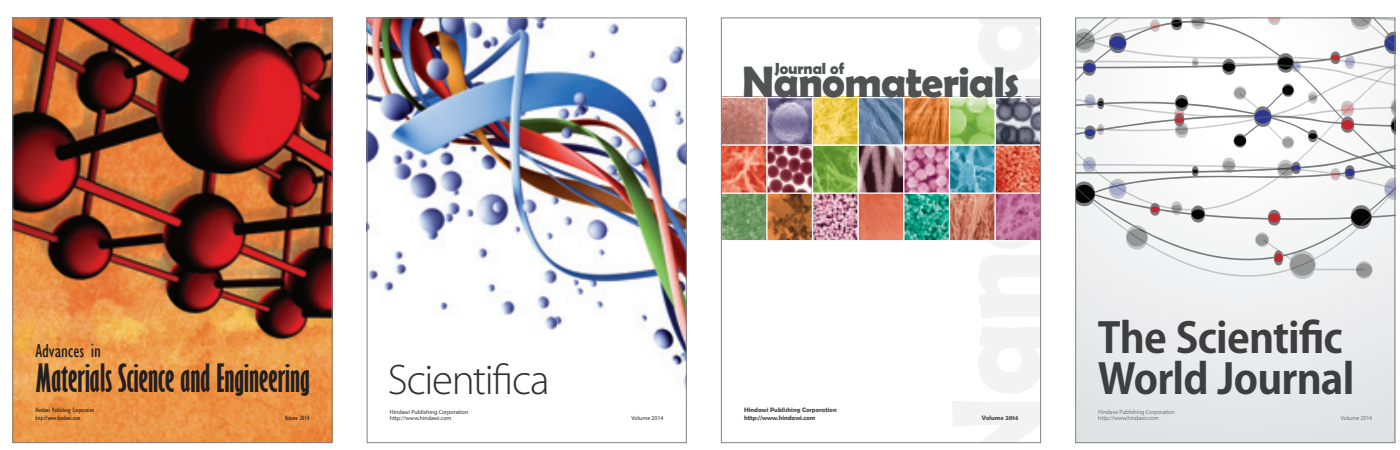

\section{The Scientific World Journal}
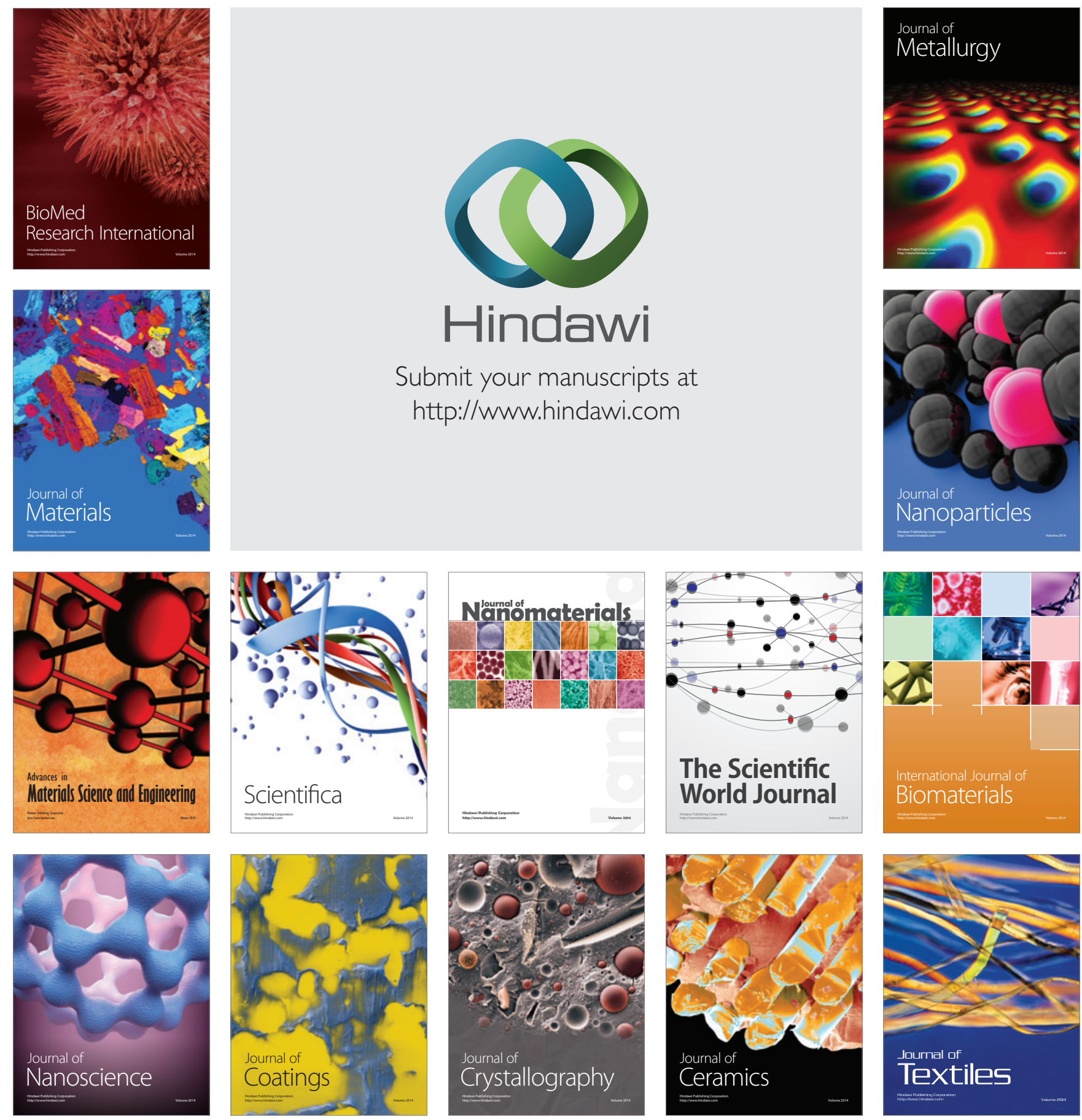